Journal of Social Sciences 4(2): 136-139, 2008

ISSN 1549-3652

(C) 2008 Science Publications

\title{
Women Leader Construction Procedure in Isan Culture of Thailand
}

\author{
${ }^{1}$ K. Wiwattanapathapi, ${ }^{1}$ J. Thammawat and ${ }^{2}$ S. Srisuntisuk \\ ${ }^{1}$ Faculty of Humanities and Social Science, Mahasarakham University, Thailand \\ ${ }^{2}$ Faculty of Humanities and Social Science, Khon Kaen University, Thailand
}

\begin{abstract}
This research aims to study the women leader construction procedure and factors that threatening and encouraging women leader in Isan culture. Analysis subjects were 14 women MP and Senator from Kalasin, Ubon Ratchathani, Maha Sarakham, Sakon Nakhon, Sri Sa Ket and Khon Kaen Provinces. From historical study on women, there was a theoretically argument on women issue which was considered to be a critical conceptual movement in the west. It was the fighting against the system that blocks women prospect and attempt to give reasons for the inferior status in society. Contrastingly, the author found that Isan women were not inferior due to the indistinguishable role performed relative to men, especially decision making power at home and outside working. Presenting the studied women history reflects that Isan women leaders need more acceptances, therefore, to be a leader is an alternative to enhance social status and to do so they must depend upon leadership construction procedure and related factors. Results found that women leader construction procedure in Isan culture comprised of 5 steps: (1) self-construct for having important role in the society, (2) build up political leader heiress, (3) faith- and trust-construct within population, (4) stronger team work construction that dependable for local people or subordinates and with good relationship between leader and followers and (5) ability to make others changes their own behavior and useful to their society.
\end{abstract}

Key words: Women leader construction procedure, Isan culture

\section{INTRODUCTION}

People who can step up into a leader must have been accumulated of merits, concentrated on public benefits. The person who used whatever stratagems for himself/herself to be a leader normally seeking for his/her own benefit. Therefore, the virtual leader cannot measure by position but, rather, the knowledge and ability of such person. Consistently, talent women often introduced to describe a high education, competency and superior than other women that might led to 'leadership' role, if the various supports gained from close relationship persons as well as economic base, but social expectations remains that the women must be talent both at home and outside (at work) while, in contrast, men will be considered the outside role only. This image can be interpreted that society adhered with the role within the family and traditional social value tightly even the social conditions now has changed a lot. The result also found two contradicting issues: in one hand the change to new industrial society gives raise to women prospect while the social and cultural changed caused women more like a commodity that is the lower status than men on the other. In reality, many women proved to have no distinct competency than men such as performing in high positions.

This study concentrated on how women leadership exists in Isan culture under the social conditions, namely women politicians and managements in the period 2544-2548?. The researchers hope to find knowledge that reflects social and cultural changes of Isan women leader on political and educational contexts and the special ability of women in stepping forward from ordinary people to social leadership that success both personal life and social life that can be a model for others to apply for an equal living society.

Who are Isan women ?: The majority of Isan women are under the conscious phrase: male is the front leg, female is the back leg or male lead, female follows even though in daughter indoctrinate also restrict on modesty which demolish women expression implicitly.

The Isan women definitions must, therefore, separates between former and present Isan women using the political revolution as an interface, therefore Isan women is referred to who lives and inborn in Isan

Corresponding Author: K. Wiwattanapathapi, Faculty of Humanities and Social Science, Mahasarakham University, Mahasarakham, 44150, Thailand 
socio-cultural context. By tracking back to the past, one can find that traditional Isan society persist in HeetKong tradition which is a life-style and influence Isan women life. The study on women status in Isan women community by Keyes found that on inheritance, women, especially the youngest daughter, must take care of parent even she has married but will not separated ( male partner will move-in and under the power of female since he must live with his wife's family ) and will received heritage more than other children.Isan culture rather has closed relationship and respect each others, of both partners' relative. It result in close relationship between the children grown up in Isan culture and relatives of maternal side and paternal side also the house reside close together making instruct, train and advice easier. The religious belief, blended between traditional belief and tradition rituals believed that most of the past rituals led by women as well as Buddhism supporting due to the women gives birth to the male child that can succeed Buddhist monkhood. Suriya Smutrkupt et al. study Mea-ying-tongtum-hook found that the boys must learn wickerwork while girls must learn cloth weaving. Marriage is a form of network building on social, economic and political cooperation. Even migrated to industrial area, Isan people, the importance of relatives unity will not decrease but in contrast it drives for superimpose group within profession groups such as taxi drivers group, Isan work force and housewife group, etc. especially there was rather limited relationship between the village and outside world in Isan society. The research study by Somsak Srisuntisuk on changing in occupation of Isan people found that the limited role for women was in household and also outside task but have less impact since the life style in the past concentrated on the relative group as the center for production and ritual including conflict solving in community. Beside, women also trains and advice new member to have profession and to be good member of the community but woman lack of chance to work publicly due to obstruction for receiving higher education therefore lack of knowledge and prospect in society.

\section{MATERIALS AND METHODS}

Turning point of Isan women: An important turning point after political revolution result from economic growth, political policy and mass media expansion which was new phenomenon that creased way for selfdevelopment gradually since, Education Act, 2464.

Specifically, Isan women have better right on education especially basic education and higher which reduced of illiterate and may widen academic knowledge, beside of housewife's, which can applied in daily life. This is a fundamental factor for status changing to be equal to men.

By focus on local utilization for better welfare even not the so-called boss and slave society anymore but capitalist and employee. The capitalist's attitude forward women only on specific aspect, however, women in industrial work forces gained more income than farmers. Women work force tends to move into Bangkok increasingly but seasonally since they will return back to rural area once the planting season begin. No objectionable that the fast growing economic has led women out of their household and some replace the conserved-for-men only so it seems that the talent women were whom who performs the same as men. At the same time the success of feminism movement has drove away the conventional ideal housewife completely.

The changes of political system resulted in enhancement of women opportunity in society and Isan women were elected in the 2492 general election. It was a historical event and being an evident nowadays women becoming equal with men and people begin to familiar with women politician, business women and therefore, changing in political system opens more chances for women in society and the wining of Isan women in participated in management team which in the past these position monopoly by men. These reflects the changing of lifestyle sustained to new one that but at the same time putting pressure on women to struggle for open up more room in society.

Diverse Isan women leaders: From biographical study of 14 women leader In politician role and education institution administrator from Kalasin, Khon Kaen , Maha Sarakham, Sakhon, Sri Sa Ket and Ubon Ratchathani Provinces found that it's not easy, to be a leader and not in the that anyone want to be can be without any readiness in term of financial, education and supporters. The selected women leader backgrounds were in-born Isan people. It does not necessary mean that all the leader concept selection proposed represent political and education classes or more important than others, rather, it base on biographical data quality that can be record with respect to distinct occupation, political path and education. It is the aim to render example of life style of women who able to step up to the front as a leader with faithful, trust and acceptance in leader role taken which scarce to find someone who can do but at least could shed the light on for other to see. Each woman leader life path from the 
hearsay found that everyone never thought of entering political path since it almost impossible and mostly thought it's the role for men but they did because they have education and economic condition of the family. For instance, Mrs. Rabiabrat Phongphanich, she can work for public due to the facilitating of her husband position while Mrs. Maliwan Nguenmuen was from poor family but with the hard working on study and after married she also received support from her husband so she was successful as same as Mrs. Maleerat Kaewka who also from poor family and struggle for self-reliance and the support on various public mass media from her husband since he own a printer company. The highest education politician (women) is Mrs. Wilawan Tunwattanaphong who finished doctorate degree, Mrs. Pensuk Juksujonda who have better economic condition after married with higher economic status, namely a diplomat from Denmark which turn her life into high society with facilitated by her husband authority. Mrs. Kusamwatj Sirikomut, who the father was the local politician, former 6 times Member of the Provincial Council while her mother was the first women Maha Sarakham Member of the Provincial Council which became foundation for the daughter to step in political path . Mrs. Oradee Suthisri from Kalasin Province, her father was a local politician and her husband is a businessman in wealthy family so playing a support role for his wife to take politician role in Kalasin Province. Additionally, some case the husband dead so the wife replaces the candidate such as the case of Mrs. Boonruen Srithares. Some case, the husband has been accumulated of merit and faith but with new regulation that limits the lowest education to be Bachelor's degree so the case of she was an MP of Sri Sa Ket Province finally while her husband continue studying to apply next time. The women administrator studied included the retired person such as Mrs. Punnce Khajornwit while Mrs. Nittaya Sripudtha is the owner and administrator of a private school. Most of women administrator finished master degree except Mrs. Punnee Khajornwit who finished Bachelor's degree. With respect to economic background, Mrs. Puongthong Phusodsri's father was a cattle trader and the wealthy family in the area; Mrs. Orathai Pathumrat, the father was the former Elementary Education Office Head, resident of Renunakhon with medium economic status; Mrs. Nittaya Sripadtha, the father was a lecturer of Maha Sarakham Teacher College, husband was a former Rector.

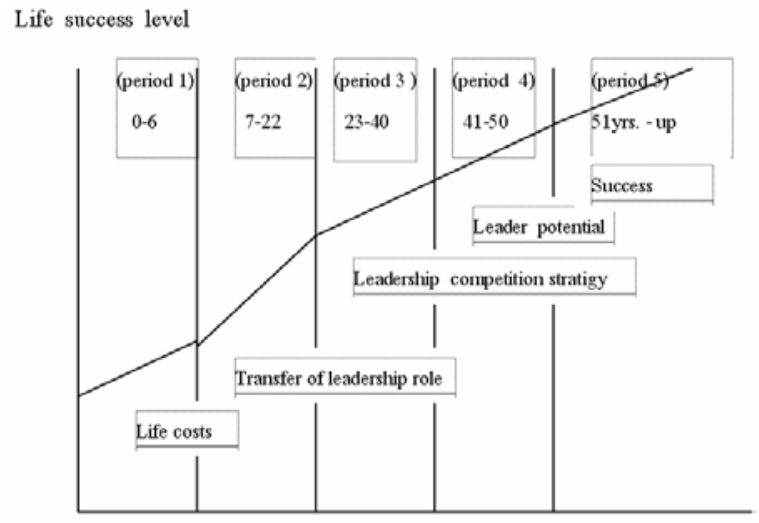

Life bases

Fig. 1: Demonstrates 5 steps of women leader construct

Life path to the Isan women leader roles: Stepping into women leader role starting from self construct, discover oneself and understood well how to success using physical, spiritual and intellectual energies. The people must have wisdom, broader vision, responsible others' fate and ready to provide assistance to others especially who has lower status. The self construct toward the success in life are as the steps in Fig 1.

First, the beginning to involve in society that generate life capital. Child-hood, must have learned, accumulate of experience and personality construct with reliability gained from family.

Second step, the heiress of political leader should carry on and even add up by accumulation of ancestor merit and faith while Education Administrators were done following successful steps.

Third step, to be a political leader must gained faith stream and confidence from public to compete the involvement area via various media to push oneself into leadership role by concentrate on grass-root people and medium level civil servants while education administrators uses patronage system, from friends and politician as well as use their financial factor to take the position.

Fourth step; maintaining of dynamic leadership both politician and education administrator using full capacity of their knowledge and competency in network building and strengthen the team work with good relationship between leader and followers, behave oneself in the correct way and utilize husband authority as a ladder to get to the leader role anticipated.

Fifth step, it is the achievement step, gained acceptance from others, ability to change others' behavior follow their own way and behave in the way 
that benefit other which considered as the highest success. The women power will be complete and virtually if other people accepted and followed.

\section{CONCLUSION}

So far, on the way to success, even the dream of many happens to be the same it proved that one may not always success. Everyone has critical point, face with various problems which discouraged them some time. If they dedicated for work might effects family life. A success women leader characteristics were that no matter how many defeats or failures but they attempt to reach the destination, no hesitate once encounter difficulty and self-construct from being ordinary people until becoming a leader. These reflects Isan women leader self-construct process under new conscious and social tendency. The virtual leader doesn't mean using power to dominate or force others to always follow them, rather, their action result in others to behave accordingly. Studying the life-style of women leader is, therefore, to reflects Isan social and cultural changes that enhance opportunity for women in society.

\section{ACKNOWLEDGEMENT}

The researchers thank Assoc. Prof. Somsak Srisuntisuk and Assoc. Prof. Jaruwan Thammawat for idea and the referees for their helpful comments.

\section{REFERENCES}

1. Porn-arun, J., 1995. Calling for women rights in Thai society 2489-2519. Master of Arts, Chulalongkorn University.

2. Srisuntisuk, S., 1992. Study on Occupation changes of Isan Rural People, Khon Kaen, Research and Development Institute, Khon Kaen University.

3. Thammawat, J., 2003. Rebellion conscious in Lao's tale in Isan Women Alternative potential and development guideline. Khon Kaen Research and Development Institute, Khon Kaen University. 